\title{
Análise fitoquímica da espécie Phyllanthus niruri L. (quebra-pedra)
}

\section{Ana Carolina de Almeida do Rosário ${ }^{1}$ e Sheylla Susan Moreira da Silva de Almeida ${ }^{2}$}

1 Graduanda do Curso de Farmácia da Universidade Federal do Amapá, Brasil. E-mail: acarolina668@gmail.com

2 Doutora de Química de Produtos Naturais. Farmacêutica-Bioquímica. Professora da Universidade Federal do Amapá, Brasil. E-mail: sheyllasusan@yahoo.com.br

RESUMO: As plantas medicinais possuem propriedades bioativas que ajudam no tratamento de doenças devido ao seu princípio ativo. Esta pesquisa buscou obtenção da análise fitoquímica da espécie Phyllanthus niruri L., conhecida popularmente como quebra-pedra e de uso medicinal popular em forma de chá para tratamento de cálculos renais, infecções intestinais e como anti-inflamatório. Após passar por processo de maceração, se obteve $0,422 \mathrm{~g}$ de extrato bruto, e a partir deste, realizou-se as análises dos principais metabólitos secundários. Após este procedimento foram identificados cinco constituintes químicos: esteroides e triterpenoides, alcaloides, depsídeos e depsidonas, açúcares redutores e antraquinonas. Relacionaram-se os mecanismos de ação obtidos na literatura dos metabólitos, com as atividades alegadas pela população da espécie em estudo. Assim, como a descoberta segundo a literatura da ação dos esteroides, como por exemplos, os heterosídeos cardioativos no tratamento de insuficiência cardíaca congestiva.

Palavras-chave: Phyllanthus niruri L., quebra-pedra, análises fitoquímicas, metabólitos secundários.

Phytochemical analysis species Phyllanthus niruri L. (break-stone) ABSTRACT: Medicinal plants are all those that have bioactive properties which help in the treatment of diseases due to its active principle. This research sought to obtain the phytochemical analysis of the species Phyllanthus niruri L. popularly known as break-stone, being popular medicinal use in tea form to treat kidney stones, intestinal infections and used as antiinflammatory. Where was obtained $0.422 \mathrm{~g}$ of crude extract after going through the maceration process. This, held the analysis of the main secondary metabolites the end of this process have been identified five of these chemical constituents: steroids and triterpenoids, alkaloids, depsides and depsidones, reducing sugars and anthraquinones. Related mechanisms of action from the literature of metabolites with the activities alleged by the population of this species. Thus, as the discovery according to the literature of action of steroids such as, for example, the cardioactive glycosides in the treatment of congestive heart failure.

Keywords: Phyllanthus niruri L., break-stone, phytochemical analysis, secondary metabolites. 


\section{INTRODUÇÃO}

A fitoquímica estuda todos os constituintes químicos e as propriedades biológicas dos vegetais, onde se tem como interesse, as análises fitoquímicas para indicação de metabólitos secundários que se encontra na espécie vegetal (SIMÕES; SPITZER, 2007). A fitoquímica também tem como objetivo 0 esclarecimento e registro dos constituintes resultantes destes vegetais, através do isolamento e elucidação de suas estruturas moleculares (LORENZI; MATOS, 2012).

As substâncias fitoquímicas são encontradas em vários alimentos consumidos pelos seres humanos como nos vegetais, nas frutas, nos legumes, nos grãos, nas sementes, e servem de proteção contra várias doenças. Sendo assim, a espécie Phylanthus niruri L., cujo nome popular é quebrapedra, pertencente ao gênero Phyllanthus e família Euphorbiaceae vem sendo estudada a longas décadas com respeito a esta indicação (MARQUES, 2010). A quebra-pedra é uma planta nativa da América, podendo ser encontrada de norte a sul do Brasil, onde cresce espontaneamente, como planta daninha e invasora com cerca de 30 a $40 \mathrm{~cm}$ de altura. Por ser facilmente encontrada em frestas, rachaduras de muros e calçadas essa planta é utilizada pela população (OLIVEIRA et al., 2012).

Segundo o conhecimento popular e como o próprio nome já diz, a planta é utilizada em forma de extrato aquoso (chá) de todas as partes para tratamento de cálculos renais, urinários e infecções intestinais (LORENZI; MATOS, 2012). Sua administração promove relaxamento dos ureteres, que aliado a uma ação analgésica, facilita a descida dos cálculos, geralmente sem dor nem sangramento, aumentando também a filtração glomerular e a excreção de ácido úrico (SIQUEIRA et al., 2012).

Os cálculos renais, a famosa pedra-norim, acontece pelo processo de cristalização que envolve nucleação, crescimento e a agregação dos cristais, além da adesão e internalização dos cristais na célula epitelial tubular (MARQUES, 2010).

Para realização deste estudo foram feitos testes fitoquímicos para identificação de metabólitos secundários na espécie tratada, onde as explicações para cada metabólito secundário identificado foi obtido através de pesquisas, a fim de entender o mecanismo e as propriedades terapêuticas que cada um possui.

O objetivo desta pesquisa foi à análise fitoquímica das folhas da espécie Phylanthus niruri L.

\section{MATERIAIS E MÉTODOS}

\subsection{Obtenção do extrato bruto}

A espécie vegetal foi coletada no dia 21 de maio de 2014, no jardim de um morador do bairro Jardim Marco Zero, no município de Macapá-AP. Foram cinco amostras para exsicata e outras cinquenta amostras encaminhada para o laboratório de Farmacognosia da Universidade Federal do Amapá (UNIFAP), campus Marco Zero, onde foram devidamente limpas e separadas para secagem sem a utilização de estufa.

Foram separadas da raiz as partes aéreas da planta, como folhas, frutos e galhos. Após a pesagem das folhas, as mesmas foram submetidas à extração por maceração, por um período de dois dias, passando em seguida para filtração. Após a filtração, para a etapa de evaporação do solvente e obtenção do extrato bruto foi utilizado um rotae- 
vaporador. Em seguida, o extrato concentrado foi acondicionado em frasco e levado para capela onde foi dessecado.

\subsection{Análises fitoquímicas}

As análises fitoquímicas foram realizadas de acordo com a metodologia empregada por Barbosa et al. (2001), na qual o extrato obtido é analisado através de reações de coloração e/ou precipitação, para identificação das principais classes de constituintes químicos. Neste estudo, foram realizados treze testes fitoquímicos, onde foram identificados no extrato apenas cinco metabólitos secundários. São eles:

\section{Esteroides e Triterpenoides}

Foram dissolvidos $3 \mathrm{mg}$ de extrato em 5 $\mathrm{mL}$ de clorofórmio e posteriormente filtrado. Transferido o extrato para um tubo de ensaio, adicionou-se $1 \mathrm{~mL}$ de anidrido acético e agitou suavemente. Em seguida, juntou 3 gotas de ácido sulfúrico $\left(\mathrm{H}_{2} \mathrm{SO}_{4}\right)$ concentrado e novamente agitou. $\mathrm{O}$ aparecimento de azul evanescente ao verde persistente indicou resultado positivo.

\section{Alcaloides}

Dissolveu-se $5 \mathrm{mg}$ do extrato em $5 \mathrm{~mL}$ de solução de $\mathrm{HCl}$ a $5 \%$ e posteriormente foi filtrado. Separaram-se três porções de $1 \mathrm{~mL}$ em tubos de ensaio e adicionaram-se de 2 a 3 gotas dos seguintes reativos:

TUBO 1: Reativo de Bouchardat. Resultado: precipitado laranja vermelho.

TUBO 2: Reativo de Dragendorff. Resultado: precipitado vermelho tijolo.

TUBO 3: Reativo de Mayer. Resultado: precipitado branco.

\section{Depsídeos e Depsidonas}

Cerca de $3 \mathrm{mg}$ do extrato bruto foram dissolvidos em $5 \mathrm{~mL}$ de éter etílico, e posteriormente foi filtrado. Evaporou-se o éter em banho maria (BM) e juntou-se ao resíduo, $3 \mathrm{~mL}$ de metanol. Agitou-se e foram adicionadas 3 gotas de solução $\mathrm{FeCl}_{3}$ a $1 \%$. O aparecimento da coloração verde, azul ou cinza indica resultado positivo.

\section{Açúcares Redutores}

Dissolveu $3 \mathrm{mg}$ do extrato em $5 \mathrm{~mL}$ de água destilada, e filtrou. Foram adicionados $2 \mathrm{~mL}$ do reativo de Fehling $A$ e $2 \mathrm{~mL}$ do reativo de Fehling $B$. Posteriormente foi aquecido em banho maria, durante 5 minutos. 0 aparecimento de um precipitado vermelho tijolo, indica a presença de açúcares redutores.

\section{Antraquinonas}

Cerca de $3 \mathrm{mg}$ foram dissolvidas em $5 \mathrm{~mL}$ de tolueno e posteriormente foi filtrado. Foram adicionados $2 \mathrm{~mL}$ de solução de $\mathrm{NH}_{4} \mathrm{OH}$ a $10 \%$, agitou-se suavemente. $\mathrm{O}$ aparecimento da coloração rósea, vermelha ou violeta, indica reação positiva.

\section{RESULTADOS E DISCUSSÕES}

Após obtenção do extrato bruto foi possível avaliar o rendimento, onde de $3,90 \mathrm{~g}$ de folha submetida a $500 \mathrm{~mL}$ de álcool absoluto, para assim conseguir após o processo de maceração obter o extrato bruto etanólico com peso de 0,42 g. A partir desse extrato se continuou um novo passo para a identificação em testes fitoquímicos dos principais metabólitos secundários da espécie Phyllanthus niruri L.

Nos testes realizados (Quadro 1) a partir da metodologia de Barbosa et al. (2001) 
foram identificados os seguintes metabólitos: esteroides e triterpenoides, alcaloides, depsídeos e depsidonas, açúcares redutores e antraquinonas.

Quadro 1 - Testes fitoquímicos realizadas para identificação dos metabólitos secundários.

\begin{tabular}{lll}
\hline Metabólitos Secundários & Positivo & Negativo \\
\hline Saponinas & & $\mathbf{x}$ \\
\hline Ácidos Orgânicos & & $\mathbf{x}$ \\
\hline Esteroides e Triterpenoides & $\mathbf{x}$ & \\
\hline Cumarinas & & $\mathbf{x}$ \\
\hline Purinas & & $\mathbf{x}$ \\
\hline Alcaloides & $\mathbf{x}$ & \\
\hline Fenóis e Taninos & & \\
\hline Depsídeos e Depsidonas & $\mathbf{x}$ & \\
\hline Açúcares Redutores & $\mathbf{x}$ & $\mathbf{x}$ \\
\hline Flavonoides & & $\mathbf{x}$ \\
\hline Proteínas e Aminoácidos & & $\mathbf{x}$ \\
\hline Antraquinonas & $\mathbf{x}$ & \\
\hline Polissacarídeos & & \\
\hline
\end{tabular}

Fonte: Autoras

Conforme descrito na literatura, as espécies vegetais podem sintetizar uma variedade de metabólitos que, por sua vez, são classificadas em grupos de acordo com sua função. Os metabólitos primários são essenciais para crescimento, desenvolvimento e garantia da sobrevivência da planta em seu habitat e os metabólitos secundários são usados para sua defesa (MIRANDA et al., 2013).

Relacionando as espécies Phyllanthus niruri L., $P$. tenellus e $P$. amarus, todas da mesma família e gênero, foi identificado na literatura a presença de alcaloides, antraquinonas, flavonoides, taninos e terpenoides, com exceção da $P$. niruri L. que não possuía alcaloides (NASCIMENTO et al, 2008). No entanto, nos testes realizados foi evidente a presença dos alcaloides no $P$. niruri L. Sendo assim, acredita-se que a au- sência e/ou presença de alcaloides provavelmente sofre influência do ambiente em que a espécie foi coletada. Assim, como os outros principais metabólitos encontrados nesta espécie que foram identificados como os açúcares redutores e depsídeos e depsidonas que a literatura, até o momento, não cita na espécie.

Em pesquisa, o que foi possível observar dentre os metabólitos identificados nesta pesquisa, à ação de alguns alcaloides, que agem inibindo a acetilcolina em efetores autônomos inervados pelos nervos pósglanglionáres colinérgicos, como na musculatura lisa, que é desprovida de inervação colinérgica. As ações antimuscarínicas, de maneira geral, tem pouco efeito nas ações de acetilcolina em receptores nicotínicos (SIMÕES; SPITZER, 2007). Também foi observada a atividade antiespasmódica de um tipo de alcaloide isolado da própria espécie $P$. niruri L. a phyllantimida, onde foi revelada a ação miorrelaxante, o que indicaria a facilitação de eliminar os cálculos renais existentes no ureter (MARQUES, 2010) e também nos distúrbios gastrointestinais (SIMÕES; SPITZER, 2007).

A classe das antraquinonas também encontrada nesta espécie é um metabólito de composição química formada a partir do ácido chiquímico e via acetato (acilpolimalonato). Sua ação terapêutica é laxativa. Provoca irritações no intestino grosso aumentando a motilidade. Este mecanismo está associado à liberação ou ao aumento da síntese de histamina, e diminuição da reabsorção de água, sendo que isto acontece com a inativação da bomba de $\mathrm{Na}+/ \mathrm{k}+-$ ATPase. Os compostos antracênicos em relação à estrutura-atividade, bem como os glicosídeos constituem as formas de transporte e de potência terapêutica reduzindo a 
lipossolubilidade de absorção. Esses compostos são liberados no intestino grosso pela flora bacteriana após a hidrólise dos glicosídeos (SIMÕES; SPITZER, 2007).

Com a identificação de esteroides na espécie, foi possível encontrar na literatura, que são de origem dos derivados do acetato. Já foram identificados mais de 40 esteróis e os mais reconhecidos em alimentos são o $\beta$-sitosterol, campesterol e o estigmasterol. Agem na redução de absorção de colesterol em dieta, com redução do risco de doenças cardiovasculares e inibição de crescimentos de certos tipos de tumores malignos (PEREIRA; CARDOSO, 2012).

$A$ ideia de os esteroides agirem contra a redução de doenças cardiovasculares vêm através dá sua ação no músculo cardíaco, ocorrendo como glicosídeos esteroidais e devido a essa ação são denominados como heterosídeos cardioativos ou cardíacos. Esses heterosídeos são usados para tratamento da insuficiência cardíaca congestiva. A ação que esse metabólito exerce sobre o músculo cardíaco está relacionada com a contratibilidade, condutibilidade e automaticidade, onde na contratibilidade há a ação inotrópica positiva (SANTOS, 2007).

Existe também a ação domotrópica negativa que age na condutibilidade e tem como relaxamento na velocidade de condução da junção atrioventricular. Já na automaticidade, existe a ação cronotrópica negativa, diminuído a frequência sinusal por efeito parassimpatomimético indireto. Sendo este, a ligação a um sinergismo com a acetilcolina e uma perturbação dos movimentos iônicos do sódio e do potássio (SIMÕES; SPITZER, 2007).

Os triterpenoides encontrados nesta análise são derivados dos terpenoides de óleos voláteis, sendo que é um composto de for- ma condensada deste, sendo sua origem biossintética do isopreno. Este composto por sua vez, também tem atividade antiespasmódica, assim como alguns alcaloides, onde esta ação relaxa a musculatura lisa intestinal, diminuindo cólicas (SIMÕES; SPITZER, 2007).

Assim, os triterpenoides têm também uma propriedade anti-inflamatória, e a literatura cita o uso da $P$. niruri L. para esta ação. $O$ processo inflamatório é geralmente acompanhado de estresse oxidativo, responsável por gerar mutações progressivas levando ao desenvolvimento tumoral. As enzimas relacionadas à inflamação são iNOS e COX-2, onde fazem a resposta dos tecidos ao dano e agentes infecciosos. A ação dos triterpenos em cima desta resposta está na diminuição destas enzimas que estão relacionados com o fator de transcrição de NFKb. Neste sentido, os triterpenos inibem a ativação destes fatores de transcrição, proporcionando uma ação anti-inflamatória, além de induzir a diferenciação celular e a apoptose, inibindo a invasão por células tumorais (GOSMANN et al., 2009).

A presença dos metabólitos secundários depsídeos e depsidonas em $P$. niruri L. vem de sua biossíntese originada do ácido orselínico. Os depsídeos é um dos exemplos de policetideos. A reação biossintética da formação deste ácido está no ácido orselínico sintase, onde seu mecanismo envolve reação de desidratação somente na etapa final quando ocorre a ciclização da cadeia para a formação deste ácido. Os depsídeos e depsidonas já foram reportadas a respeito de atividades anti-inflamatória e antibiótica. Devido a essas atividades, estes metabólitos vêm sendo sintetizados para avaliações de suas respectivas atividades biológicas e 
possibilidade de uso farmacológico (MEDEIROS, 2010).

Os testes para açúcares redutores, substâncias que fazem parte dos grupos dos carboidratos, caracterizam-se por possuírem grupo carbonílico e cetônico livres, capazes de se oxidarem na presença de agentes oxidantes em soluções alcalinas. Os monossacarídeos, glicose e frutose são açúcares redutores (SILVA; MONTEIRO; ALCANFOR, 2003). São importantes nas plantas, principalmente, em situações de déficit hídrico, pois propiciam um aumento na síntese de sacarose que contribui com o ajuste osmótico sem inibir a fotossíntese.

Dentre os principais mecanismos contra os cálculos renais e infecções intestinais, encontrou-se em pesquisa apenas alcaloides e antraquinonas, triterpenoides e os depsídeos e depsidonas na atividade antiinflamatória, além dos esteroides como heterosídeos cardíacos agindo na musculatura cardíaca como propriedade terapêutica. As análises realizadas não impendem a continuidade do estudo para identificar as propriedades terapêuticas dos outros metabólitos encontrados a partir deste relatório para outras doenças além das já citadas.

\section{CONCLUSÃO}

A espécie Phyllanthus niruri L. conhecida popularmente como quebra-pedra utilizada como forma de extrato aquoso (chá), para cálculos renais e outras doenças, após a realização dos testes fitoquímicos, foi possível confirmar a ocorrência dos principais metabólitos secundários como esteroides e triterpenoides, alcaloides, depsídeos e depsidonas, açúcares redutores e antraquinonas. No entanto, constatou-se que para saponinas, ácidos orgânicos, cumarinas, puri- nas, fenóis e taninos, flavonoides, proteínas, aminoácidos e polissacarídeos, as análises aplicadas deram resultado negativo. $\mathrm{Na}$ literatura consultada foi possível constatar a ação terapêutica dos alcaloides como atividade antiespasmódica, tendo uma ação miorrelaxante, o que facilita a saída do cálculo renal e a antraquinona como laxativos e catárticos para infecções intestinais. Os triterpenoides derivados dos terpenoides e depsídeos e depsidonas agindo na atividade anti-inflamatória, além dos esteroides com a sua denominação de heterosídeos cardioativos agindo na musculatura cardíaca no tratamento da insuficiência cardíaca congestiva.

Portanto, foi possível observar na pesquisa literária que não há indícios de açúcares redutores, depsídeos e depsidonas na espécie retratada, mas as análises feitas revelaram a presença destas substâncias, o que acredita ser provavelmente uma influência do ambiente no qual foi coletada. No entanto, este resultado não descarta a possibilidade de novas pesquisas que envolvam os metabólitos encontrados na espécie estudada.

\section{AGRADECIMENTOS}

Ao Programa de Educação Tutorial - PET. Ao grupo PET- Farmácia da UNIFAP. Ao Programa Pesquisa para o SUS - PPSUS.

\section{REFERÊNCIAS}

BARBOSA, W. L. R., et al., Manual Para Análise Fitoquímica e Cromotográfica de Extratos Vegetais. Revista Cientifica da UFPA, 2001.

GOSMANN, G.; et al. Derivados oleananos e ursanos e sua importância na descoberta de 
novos fármacos com atividade antitumoral, anti-inflamatória e antioxidante. Química Nova. v. 32, n. 5, p. 1245-1252, 2009. LORENZI, H.; MATOS, F. J. A. Plantas medicinais no Brasil: nativas e exóticas. 2. ed. Nova Odessa: Instituto Plantarum, 2012. $576 p$.

MARQUES, L. C. Phyllanthus niruri (QuebraPedra) no Tratamento de Urolitíase: Proposta de Documentação para Registro Simplificado como Fitoterápico. Revista Fitos, v. 5, n. 03, p. 20-33, 2010.

MEDEIROS, L. S. Estudo químico e biológico de microorganismos endofíticos associados às frutas banana, pêra e goiaba. São Carlos, SP, 2010. Originalmente apresentada como dissertação de mestrado, Universidade Federal de São Carlos, 2010.

MIRANDA, G. S.; et al. Atividade antibacteriana in vitro de quatro espécies vegetais em diferentes graduações alcoólicas. Revista Brasileira de Plantas Medicinais. v. 15, n. 1, p. 104-111, 2013.

NASCIMENTO, J. E.; et al. Estudo fitoquímico e bioensaio toxicológico frente a larvas de Artemia salina Leach. de três espécies medicinais do gênero Phyllanthus (Phyllanthaceae). Revista de Ciências Farmacêutica Básica e Aplicada. v. 29, n. 2, p. 145-150, 2008.

OLIVEIRA, B. E. D.; et al. Estudo Fitoquímico e avaliação da atividade antibacteriana de Phyllanthus Niruri (Quebra - Pedra) em Escherichia coli. In: Congresso Norte e Nordeste de Pesquisa e Inovação. Anais... 7, 2012, Palmas, TO.

PEREIRA, R. J.; CARDOSO, M. G. Metabólitos secundários vegetais e benefícios antioxidantes. Journal of Biotechnology and Biodiversity. v. 3, n. 4, p. 146-152, 2012.

SANTOS, R. I. Metabolismo básico e de origem dos metabólitos secundários. In: SI-
MÕES, C. M. O. et al. Farmacognosia, da planta ao medicamento. 6. Ed. Porto Alegre: Editora da UFRGS; Florianópolis: Editora da UFSC, 2007. Cap. 16.

SIMÕES, O. M. C.; SPITZER, V. Óleos voláteis. In: SIMÕES, C. M. O. et al. Farmacognosia, da planta ao medicamento. 6 . Ed. Porto Alegre: Editora da UFRGS; Florianópolis: Editora da UFSC, 2007. Cap. 18.

SIQUEIRA, J. M.; et al. Centro de Informação sobre Medicamentos, Plantas Medicinais e Tóxicas. 11 ed. Divinópolis, MG: Ed. da UFSJ, 2012.

SILVA, R. N.; MONTEIRO, V. N.; ALCANFOR, J. D. X. Comparação de métodos para a determinação de açúcares redutores e totais no mel. Ciência e Tecnologia dos Alimentos. Campinas, v. 23 , n. 3 , p. $337-341$, 2003.

\section{(c) (i) \\ License information: This is an open- access article distributed under the terms of the Creative Commons Attribution License, which permits unrestricted use, distribution, and reproduction in any medium, provi- ded the original work is properly cited.}

Artigo recebido em 18 de setembro de 2014 .

Avaliado em 10 de março de 2016.

Aceito em 21 de março de 2016.

Publicado em 25 de maio de 2016.

Como citar este artigo (ABNT):

ROSÁRIO, Ana Carolina de Almeida do; ALMEIDA, Sheylla Susan Moreira da Silva de. Análise fitoquímica da espécie Phyllanthus niruri L. (quebra-pedra). Estação Científica (UNIFAP), Macapá, v. 6, n. 1, p. 35-41, jan./abr. 2016. 